Iustitia Socialis. Revista Arbitrada de Ciencias Jurídicas.

Año VI. Vol. VI. N ${ }^{\circ} 10$. Enero - Junio. 2021

Hecho el depósito de Ley: FA2016000064

ISSN: 2542-3371

FUNDACIÓN KOINONIA (F.K). Santa Ana de Coro, Venezuela;

Maribel José Giménez-Guariguata

http://dx.doi.org/10.35381/racji.v6i10.1152

\title{
Las Ciencias Jurídicas y Criminalísticas en el desarrollo de la Sociedad
}

Se recoge en este número, los problemas éticos, jurídicos y prácticos que apuntan a la criminología, derechos penal y que rodea a los Derechos humanos, que han surgido a causa del reconocimiento y de la aplicación de los Derechos humanos; puntos centrales de observación, en torno a los cuales se han centrado las reflexiones de los distintos autores en cada uno de sus artículos, por los requerimientos que han sido suscitados por diversas ocasiones, por experiencias vitales y por exigencias culturales. Por tanto, cada artículo recoge las dos dimensiones, a lo largo de las cuales se han efectuado las investigaciones, esto es, la relativa al campo de la criminología y el derecho Penal sustantivo que incide en los Derechos humanos, y la referida a las modalidades técnicas de su empleo en los procedimientos valorativos.

El primer centro de interés, de tales problemas, esto es, el propiamente teórico, lo constituye la exigencia fundamental de conocer cuál es la consistencia ideal de los nuevos derechos, cuál es la densidad de su validez en la conciencia jurídica y como toman forma y se manifiestan en la realidad de la legislación con respecto a la sociedad. Estamos muy cerca del ocaso del siglo en que los derechos humanos recibieron un reconocimiento de carácter universal, en el sentido preciso y concreto del término, es decir, de extensión planetaria; mientras ellos en un comienzo se presentaban en su condición de universalidad filosófica, en realidad no eran sino privilegio de los miembros de naciones o de sectores sociales dominantes, a los cuales correspondía su ejercicio exclusivo. Hoy los derechos humanos se atribuyen a todos los hombres en toda la Tierra, inclusive a aquellos que ignoran su nombre o que desconocen su mérito, y por ende todas las conductas que realiza el hombre responden a una relación de causa efecto que pueden llevar a Delitos y faltas sancionados por cada legislación.

No basta saber cuál es el significado de los derechos humanos, pues también debe reconocerse cuál es su funcionamiento en la práctica, y deben descubrirse los métodos 
de una técnica de valoración de esos derechos en la experiencia real, después que se han convertido en elemento esencial e indefectible en el contexto del ordenamiento internacional y de los ordenamientos estatales. Ellos representan las nuevas reglas de juicio, ya sea ético o jurídico, puesto que los dos términos corresponden a los dos aspectos conjuntos de los derechos humanos, que sirven como metro cognoscitivo y como regla operativa en el circulo vital que se forma entre la verdad y el hecho, entre la teoría y la práctica, y en el cual consiste el derecho en cuanto aplicación de las formas jurídicas en la practica social. En efecto, el derecho es una estructura que transporta la experiencia común, pero es también una técnica de promoción, de control y de represión de los comportamientos humanos.

En estos escritos que se presentan en este número, se presenta al hombre de la sociedad tecnológica, de la sociedad de la información, del Estado de bienestar, se define como el hombre artificial por su nueva imagen interior, que lo hace sentir distinto del hombre encerrado en el seno de la naturaleza; y podría, no obstante, definirse, por su eficacia inventiva, como homo artifex, de un mundo nuevo, material y moral, en el cual el progreso de la sociedad tiene sus estandartes en los derechos humanos, pero que sus acciones 0 sus omisiones hacen aventurarnos en el mundo de la criminalidad.

\section{Dra. Maribel José Giménez-Guariguata iustitiasocialis@fundacionkoinonia.com.ve Red de Investigación Koinonía, Santa Ana de Coro Venezuela https://orcid.org/0000-0002-2178-9384}

